\title{
The Danish Hip Arthroplasty Register
}

This article was published in the following Dove Press journal:

Clinical Epidemiology

25 October 2016

Number of times this article has been viewed

\section{Per Hviid Gundtoft ${ }^{1-3}$ Claus Varnum ${ }^{4}$ \\ Alma Becic Pedersen ${ }^{5}$ Søren Overgaard ${ }^{2,3}$}

'Department of Orthopedics, Kolding Hospital, Kolding, ${ }^{2}$ Department of Orthopedic Surgery and

Traumatology, Odense University Hospital, ${ }^{3}$ nstitute of Clinical

Research, University of Southern Denmark, Odense, ${ }^{4}$ Department of Orthopedics, Vejle Hospital, Vejle, ${ }^{5}$ Department of Clinical Epidemiology, Aarhus University Hospital, Aarhus, Denmark
Correspondence: Per Hviid Gundtoft Department of Orthopedics, Kolding Hospital, Skovvangen 2-8, 6000 Kolding, Denmark

Tel +4526195512

Email per.hviid.gundtoft@rsyd.dk
Aim of database: The aim of the Danish Hip Arthroplasty Register (DHR) is to continuously monitor and improve the quality of treatment of primary and revision total hip arthroplasty (THA) in Denmark.

Study population: The DHR is a Danish nationwide arthroplasty register established in January 1995. All Danish orthopedic departments - both public and private - report to the register, and registration is compulsory.

Main variables: The main variables in the register include civil registration number, indication for primary and revision surgery, operation date and side, and postoperative complications. Completeness of primary and revision surgery is evaluated annually and validation of a number of variables has been carried out.

Descriptive data: A total of 139,525 primary THAs and 22,118 revisions have been registered in the DHR between January 1, 1995 and December 31, 2014. Since 1995, completeness of procedure registration has been high, being $97.8 \%$ and $92.0 \%$ in 2014 for primary THAs and revisions, respectively. Several risk factors, such as comorbidity, age, specific primary diagnosis and fixation types for failure of primary THAs, and postoperative complications, have been identified through the DHR. Approximately 9,000 primary THAs and 1,500 revisions are reported to the register annually.

Conclusion: The DHR is important for monitoring and improvement of treatment with THA and is a valuable tool for research in THA surgery due to the high quality of prospective collected data with long-term follow-up and high completeness. The register can be used for population-based epidemiology studies of THA surgery and can be linked to a range of other national databases.

Keywords: Danish Hip Arthroplasty Register, validation, completeness

\section{Aim of database}

The Danish Hip Arthroplasty Register (DHR) was initiated by the Danish Orthopedic Society in 1994, in cooperation with the Danish Health and Medicine Authority and the previous Danish Counties. Data collection began on January 1, 1995. The aim of the database is to monitor and improve the quality and outcome of total hip arthroplasty (THA) in Denmark by examining the epidemiology of THA surgery, identifying risk factors for revision, death, and postoperative complications, estimating implant survival, and facilitating improvement of THA surgery and comparison between departments. ${ }^{1}$

The present paper aimed to describe the organization, content, and quality of DHR and thereby illustrate the potential and usefulness of the DHR for monitoring of quality and performing clinical epidemiological research. 


\section{Materials and methods}

\section{Study population}

In the DHR, primary THA is defined as the first implantation of a THA. From the beginning of the register, it was decided that only data on THA should be included in the register. Revision is defined as any later surgical procedure involving the primary THA, including change of any component or debridement without removal of any part of the prosthesis. Reporting of procedures to the DHR is compulsory for all public orthopedic departments and private clinics in Denmark, and the reporting is done by the surgeon immediately after surgery. DHR is approved as a national clinical quality database, which according to Danish legislation number 546 from June 24, 2005, is allowed to collect surgical and patient related data into DHR without consent from the patient.

Upon birth or immigration, all Danish citizens are given a unique and unchangeable civil registration number, which is recorded for all health care contacts in Denmark. The civil registration number allows for linkage between the DHR and other national databases. The DHR is linked to the Civil Registration System, which holds information on vital status, date of migration, or death, thereby allowing for analysis of implant survival with complete follow-up.

\section{Main variables}

Since the beginning of data collection, variables have been changed a number of times to have relevant analyses and results for the surgeons. However, the majority of variables - including all the main variables - have remained unchanged.

The main preoperative variables include: the civil registration number - in which birthday and sex are included - indication for primary procedure, and previous surgery on the hip.

The main perioperative variables for primary and revision surgery include: date of surgery, operation side, type of anesthesia, antibiotic prophylactic treatment, surgical approach, duration of surgery, type of components and their fixation, and perioperative complications, such as acetabular or femoral fracture.

For revisions, the main variables include: indication for revision, previous surgery, extent of surgery, and number of previous revisions. Primary THA can be directly linked to any subsequent revision by the use of the unique and unchangeable civil registration number and registered operation side.

The complete list of the variables in the DHR is shown in Table 1.

\section{Validation of completeness and coverage}

As registration to the DHR is compulsory, the register has complete coverage on a national level in principle, but a very small number of departments do not report to the register.
Table I The main variables in the Danish Hip Arthroplasty Register

\begin{tabular}{|c|c|}
\hline Name of the variable & Description of the variable \\
\hline Civil registration number & Unique number including age and sex \\
\hline \multirow[t]{2}{*}{ Type of operation } & I. Primary \\
\hline & 2. Revision \\
\hline \multirow[t]{2}{*}{ Operation side } & I. Right \\
\hline & 2. Left \\
\hline \multirow[t]{2}{*}{ Previous surgery on hip } & I. No \\
\hline & 2. Yes \\
\hline \multirow[t]{6}{*}{ Type of previous surgery } & $\begin{array}{l}\text { I. Osteosynthesis of proximal femur } \\
\text { fracture }\end{array}$ \\
\hline & 2. Hemiarthroplasty \\
\hline & 3. Osteosynthesis of acetabular fracture \\
\hline & 4. Proximal femur osteotomy \\
\hline & 5. Total hip arthroplasty \\
\hline & 6. Other \\
\hline \multirow[t]{7}{*}{ Primary diagnosis } & I. Osteoarthritis \\
\hline & $\begin{array}{l}\text { 2-4. Fracture of either femur or } \\
\text { acetabulum }\end{array}$ \\
\hline & 5. Traumatic dislocation of the hip \\
\hline & 6. Avascular necrosis of the femoral head \\
\hline & 7-9. Different types of arthritis \\
\hline & 10-13. Different types of congenital hip \\
\hline & disorder \\
\hline Harris Hip Score & Score \\
\hline Operation date & dd.mm.yyyy \\
\hline \multirow[t]{2}{*}{ Operation theater } & I. Laminar flow \\
\hline & 2. Conventional \\
\hline \multirow[t]{2}{*}{ Type of preoperative antibiotics } & I. None \\
\hline & 2-16. Type of antibiotics \\
\hline Duration of antibiotic & I. Only preoperatively \\
\hline \multirow[t]{2}{*}{ treatment } & 2. Max. 24 hours \\
\hline & 3. $>24$ hours \\
\hline \multirow[t]{4}{*}{ Type of anesthesia } & I. General \\
\hline & 2. Spinal or epidural \\
\hline & 3. Combined \\
\hline & 4. Other \\
\hline \multirow[t]{2}{*}{ Anticoagulants } & I. None \\
\hline & 2. Type \\
\hline \multirow[t]{3}{*}{ Hemorrhage prophylaxis } & I. None \\
\hline & 2. Tranexamic acid \\
\hline & 3. Other \\
\hline Duration of surgery & Minutes \\
\hline \multirow[t]{4}{*}{ Approach } & I. Posterior \\
\hline & 2. Anterior \\
\hline & 3. Lateral \\
\hline & 4. Other \\
\hline \multirow[t]{2}{*}{ Acetabular component } & I. With holes \\
\hline & 2. Without holes \\
\hline $\begin{array}{l}\text { Fixation of acetabular } \\
\text { component }\end{array}$ & $\begin{array}{l}\text { I-7. With/without cement and with/ } \\
\text { without screws }\end{array}$ \\
\hline Femoral component & Type of component \\
\hline Fixation of femoral component & I-5. With/without cement \\
\hline Perioperative complication & I. None \\
\hline acetabulum & 2. Yes \\
\hline $\begin{array}{l}\text { Perioperative complication } \\
\text { femur }\end{array}$ & $\begin{array}{l}\text { I-6. None, fissure/fracture with/ } \\
\text { without osteosynthesis }\end{array}$ \\
\hline Femoral head diameter & $\mathrm{mm}$ \\
\hline
\end{tabular}

(Continued) 
Table I (Continued)

\begin{tabular}{|c|c|}
\hline Name of the variable & Description of the variable \\
\hline \multirow[t]{3}{*}{ Femoral head made of } & I. Metal \\
\hline & 2. Ceramic \\
\hline & 3. Other \\
\hline \multirow[t]{3}{*}{ Type of liner } & I. Polyethylene \\
\hline & 2. Ceramic \\
\hline & 3. Metal \\
\hline \multirow[t]{9}{*}{ Indication for revision } & I-6. Aseptic loosening of one or both \\
\hline & components with/without osteolysis \\
\hline & 7. Osteolysis without loosening \\
\hline & 8. Prosthetic joint infection \\
\hline & 9. Femoral fracture \\
\hline & 10. Dislocation \\
\hline & II. Component failure \\
\hline & 12. Pain \\
\hline & 13. Other \\
\hline \multirow[t]{6}{*}{ Previous implant status } & I. Cement \\
\hline & 2. Cementless \\
\hline & 3 and 4. Hybrid \\
\hline & 5. Girdlestone \\
\hline & 6. Spacer \\
\hline & 7. Other \\
\hline Number of previous revisions & Number \\
\hline
\end{tabular}

Every third month, data in the DHR are analyzed, and completeness is assessed using the National Patient Register (NPR) as reference. Surgical procedures reported to the NPR by departments are reimbursed by the Danish National Health and Medicine authorities through the diagnosis-related group system which motivates departments for reporting to the NPR.

All departments performing either primary or revision THAs receive a monthly update on missing registration of procedures in the DHR and are requested to report missing registration to the DHR. The goal of the DHR is to achieve registration completeness of more than $90 \%$ for both primary and revision THA on a national, regional, and departmental level, according to a notification in 2006 on the improvement of nationwide and regional clinical quality databases passed by the National Board of Health.

\section{Results}

The DHR publish an annual report which contains data from the year 1995 and onwards, up-dated with data from the previous year. In the annual report of 2015, 139,525 primary THAs and 22,118 revisions have been reported between January 1, 1995 and December 31, 2014. ${ }^{2}$ Each year, 9,000 primary THAs and 1,500 revisions are reported to the register.

\section{Coverage}

In 2014, 44 departments performed primary THA, and 41 of these reported to the DHR. The number of primary THAs in the remaining three departments was 58 procedures out of 9,830 reported procedures indicating that the involved departments are very small. ${ }^{2}$

\section{Completeness}

Completeness has been high from the beginning, with 94\% for primary THA and $81 \%$ for revision in the first 6 years of registration. ${ }^{3}$

On a national level, completeness for primary THA has increased to $97.8 \%$ in 2014, and completeness for revisions has increased to $92.0 \%$, when using the NPR as reference. If adjusted for misclassifications in the NPR, where a primary THA is registered as a revision due to previous osteosynthesis or hemiarthroplasty, the completeness for revisions increases to $96.0 \%{ }^{2}$

All five regions in Denmark fulfill the requirement of $90 \%$ completeness for primary THAs.

There are very few departments which do not honor the demands of $90 \%$ completeness of both primary and revision THAs.

\section{Analysis of variables}

The most common indication is primary osteoarthritis in patients who experience pain, reduced level of activity, and quality of life accounting for $78 \%$ followed by fracture of the proximal femur accounting for $12 \%$. In recent years, an increasing number of femoral neck fractures have been treated with THA.

In all, $96 \%$ of THAs are performed through a posterior approach. From 1995 to 2004, cemented fixation was most commonly used (50\%), as compared to hybrid (28\%) and cementless (22\%). However, there has been a shift toward the use of more cementless designs, which since 2011 have accounted for up to $70 \%$ of all primary THAs (Figure 1).

A metal femoral head is the most commonly used (93\%). In the last 10 years, there has been a trend toward using

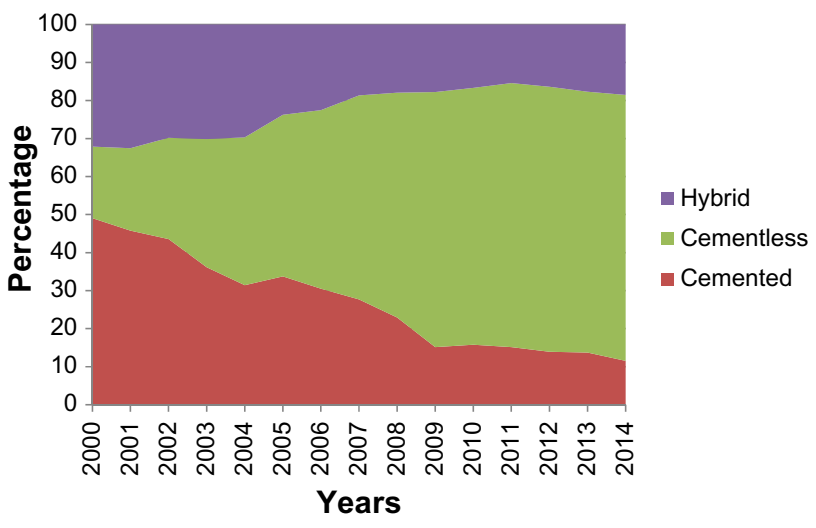

Figure I Type of operation in primary total hip arthroplasty. 
larger femoral head sizes, from the $28 \mathrm{~mm}$ being the most commonly used in $2004(87 \%)$ to a 32 or $36 \mathrm{~mm}$ diameter representing the majority $(85 \%)$ in 2014 .

The requirement for blood transfusion has decreased dramatically from $21.3 \%$ in 2006 to $8.5 \%$ in 2014 . Revision within 2 years after primary surgery and readmission have shown a rather large variation between departments, which resulted in a call for an audit in a number of departments.

\section{Follow-up}

Survival of primary THAs with 18 years follow-up is 83\% (95\% confidence interval [CI]: $82 \%-84 \%)$ and with 10 years follow-up $92 \%$ (95\% CI: $92 \%-93 \%)$, based on the Kaplan-Meier analyses with time to first revision as outcome (Figure 2). The most common indication for revision is aseptic loosening (53\%), followed by dislocation of the hip (17\%) and prosthetic joint infection (9\%).

\section{Examples of research}

Previous research

Since the beginning in 1995 , more than 40 papers have been published based on the DHR data linked to other Danish medical databases, such as the NPR, the Civil Registration System, the Danish Transfusion Database, and the Danish Prescription Database. The studies have primarily focused on validation of data in the register, ${ }^{3}$ describing the outcome, ${ }^{4}$ and the epidemiology of THA surgery. ${ }^{5,6}$ A number of risk factors for revision have been studied ${ }^{7,8}$ and so has risk for postoperative complications, such as mortality, venous thromboembolism, myocardial infarction, and stroke. ${ }^{9,10}$

\section{Present research}

The DHR does not offer financial support for research purposes, and research from the register is in most cases performed in collaboration with the Department of Clinical Epidemiology, Aarhus University Hospital and $\mathrm{PhD}$ students and cooperation with members of DHR steering committee. In 2015, four ongoing $\mathrm{PhD}$ students are using data from the DHR. They have identified the "true" incidence of prosthetic joint infection, ${ }^{11}$ described the epidemiology and outcome of fast track setting in Denmark, ${ }^{12}$ found that ceramic-onceramic does not have a greater risk of revision compared to metal-on-polyethylene bearings, ${ }^{13}$ and identified cirrhosis as a risk factor for postoperative complications. ${ }^{14}$

\section{Administrative issues and funding}

The steering committee of the DHR consists of an orthopedic surgeon from each of the five Danish Regions, a representative from the Danish Society for Hip and Knee Arthroplasty and the Danish Orthopedic Society, a representative for the Competence Centre North, Department of Clinical Epidemiology, Aarhus University Hospital, and a representative for Central Denmark Region. All research protocols, in which data from the DHR are used, must be approved by the steering committee before an initiation of a project.

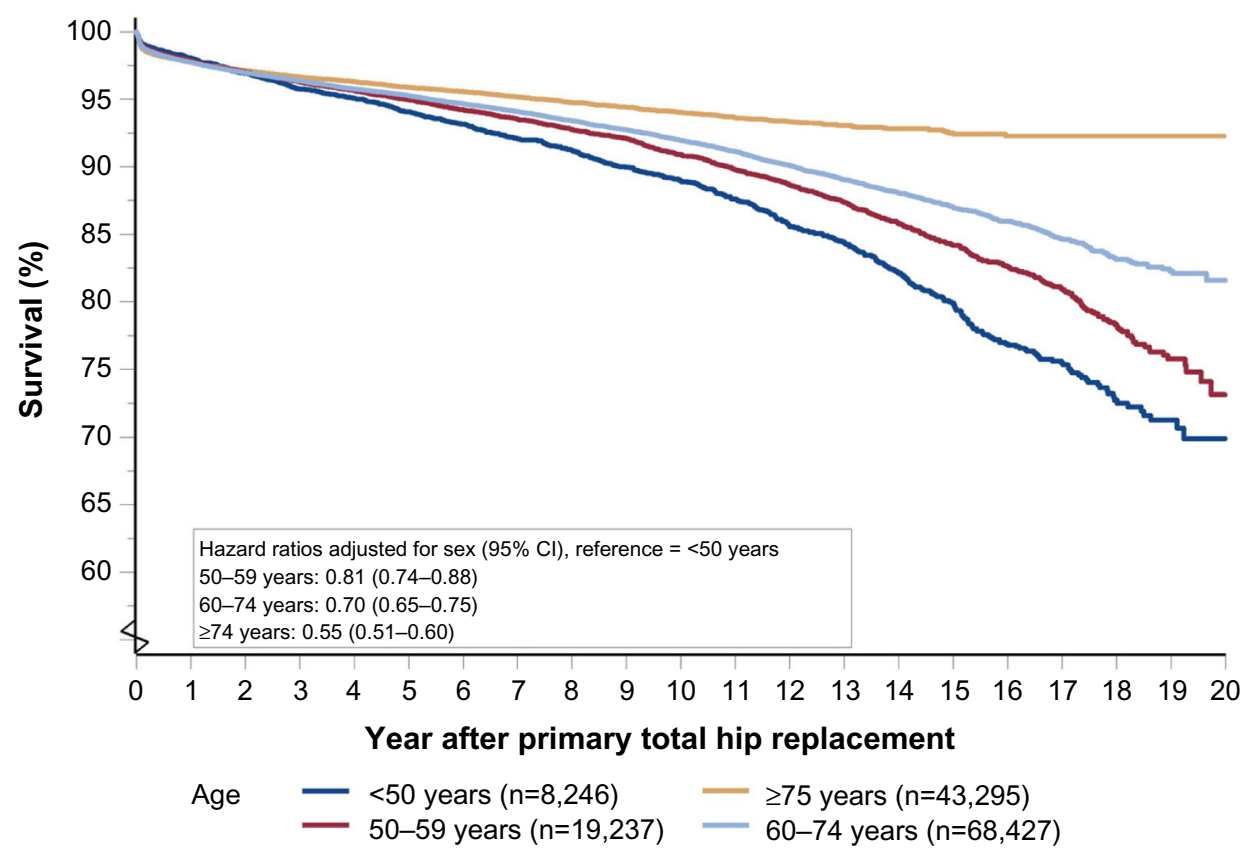

Figure 2 Surveillance graph of all primary total hip arthroplasties $(n=139,295)$.

Abbreviation: $\mathrm{Cl}$, confidence interval. 
The DHR publishes an annual report, which is distributed to all Regions, Danish Health and Medicines Authority, all participating departments, and the Danish Orthopaedic Society. The results are presented at the Annual Congress of the Danish Orthopaedic Society. The DHR shares the budget with the three other orthopedic databases included in the Danish Common Orthopedic Database, which has an annual budget of $\sim 1.2$ million Danish kroner (€160,000), received from the Danish Regions.

\section{Cooperation with other databases}

The DHR cooperates with the Nordic Arthroplasty Register Association. ${ }^{15}$ The collaboration started in 2008 among the DHR, the Swedish Hip and Knee Arthroplasty Register, and the Norwegian Arthroplasty Register. The Finnish Arthroplasty Register joined in 2010. Besides comparison of national difference in patient demographics, operation methods, and choice of implant, this register association offers a high volume of primary THA and revision data. Seventeen papers have been published using data from the register.

\section{Conclusion}

The DHR is important for the monitoring of treatment with THA as the register holds prospective collected validated data with a long-term follow-up and high completeness. The DHR can be linked to a wide range of other national databases, and therefore the register is a valuable tool for research of THA surgery and quality improvement. Data from the DHR have been used to describe the epidemiology and trends in THA surgery, and identify risk factors for revision, death, and postoperative complications.

\section{Acknowledgments}

The authors thank the steering committee and all orthopedic departments in Denmark for their cooperation with the DHR. This paper was funded by the Program for Clinical Research Infrastructure (PROCRIN) established by the Lundbeck Foundation and the Novo Nordisk Foundation and administered by the Danish Regions.

\section{Author contributions}

$\mathrm{PHG}, \mathrm{CV}, \mathrm{ABP}$, and SO participated in the design, analysis of data, and revision of the manuscript. All authors have approved the final manuscript and are accountable for all aspects of the work.

\section{Disclosure}

The authors report no conflicts of interest in this work.

\section{References}

1. Lucht U. The Danish Hip Arthroplasty Register. Acta Orthop Scand. 2000;5(71):433-439.

2. Danish Hip Arthroplasty Register: Annual Report 2015. Available from: https://www.sundhed.dk/content/cms/98/4698_dhr\%C3\%A5rsrapport-2014_final.pdf. Accessed April 16, 2015.

3. Pedersen A, Johnsen S, Overgaard S, Soballe K, Sorensen HT, Lucht U. Registration in the Danish Hip Arthroplasty Registry: completeness of total hip arthroplasties and positive predictive value of registered diagnosis and postoperative complications. Acta Orthop Scand. 2004;75(4):434-441.

4. Nikolajsen L, Brandsborg B, Lucht U, Jensen TS, Kehlet H. Chronic pain following total hip arthroplasty: a nationwide questionnaire study. Acta Anaesthesiol Scand. 2006;50(4):495-500.

5. Pedersen AB, Johnsen SP, Overgaard S, Soballe K, Sorensen HT, Lucht U. Total hip arthroplasty in Denmark: incidence of primary operations and revisions during 1996-2002 and estimated future demands. Acta Orthop. 2005;76(2):182-189.

6. Pedersen AB, Johnsen SP, Overgaard S, Soballe K, Sorensen HT, Lucht U. Regional variation in incidence of primary total hip arthroplasties and revisions in Denmark, 1996-2002. Acta Orthop. 2005;76(6):815-822.

7. Johnsen SP, Sorensen HT, Lucht U, Soballe K, Overgaard S, Pedersen AB. Patient-related predictors of implant failure after primary total hip replacement in the initial, short- and long-terms. A nationwide Danish follow-up study including 36,984 patients. J Bone Joint Surg Br. 2006;88(10):1303-1308.

8. Pedersen AB, Mehnert F, Johnsen SP, Sorensen HT. Risk of revision of a total hip replacement in patients with diabetes mellitus: a populationbased follow up study. J Bone Joint Surg Br. 2010;92(7):929-934.

9. Pedersen AB, Mehnert F, Sorensen HT, Emmeluth C, Overgaard S, Johnsen SP. The risk of venous thromboembolism, myocardial infarction, stroke, major bleeding and death in patients undergoing total hip and knee replacement: a 15 -year retrospective cohort study of routine clinical practice. Bone Joint J. 2014;96-B(4):479-485.

10. Pedersen AB, Sorensen HT, Mehnert F, Johnsen SP, Overgaard S. Effectiveness and safety of different duration of thromboprophylaxis in 16,865 hip replacement patients - a real-word, prospective observational study. Thromb Res. 2015;135(2):322-328.

11. Gundtoft PH, Overgaard S, Schonheyder HC, Moller JK, KjaersgaardAndersen P, Pedersen AB. The "true" incidence of surgically treated deep prosthetic joint infection after 32,896 primary total hip arthroplasties. Acta Orthop. 2015;86(3):326-334.

12. Glassou EN, Pedersen AB, Hansen TB. Risk of re-admission, reoperation, and mortality within 90 days of total hip and knee arthroplasty in fast-track departments in Denmark from 2005 to 2011. Acta Orthop. 2014;85(5):493-500.

13. Varnum C, Pedersen AB, Kjaersgaard-Andersen P, Overgaard S. Comparison of the risk of revision in cementless total hip arthroplasty with ceramic-on-ceramic and metal-on-polyethylene bearings. Acta Orthop. 2015;86(4):477-484.

14. Deleuran T, Vilstrup H, Overgaard S, Jepsen P. Cirrhosis patients have increased risk of complications after hip or knee arthroplasty. Acta Orthop. 2015;86(1):108-113.

15. Havelin LI, Robertsson O, Fenstad AM, Overgaard S, Garellick G, Furnes O. A Scandinavian experience of register collaboration: the Nordic Arthroplasty Register Association (NARA). J Bone Joint Surg Am. 2011;93(Suppl 3):13-19. 


\section{Publish your work in this journal}

Clinical Epidemiology is an international, peer-reviewed, open access, online journal focusing on disease and drug epidemiology, identification of risk factors and screening procedures to develop optimal preventative initiatives and programs. Specific topics include: diagnosis, prognosis, treatment, screening, prevention, risk factor modification,

Submit your manuscript here: http://www.dovepress.com/clinical-epidemiology-journal systematic reviews, risk \& safety of medical interventions, epidemiology \& biostatistical methods, and evaluation of guidelines, translational medicine, health policies \& economic evaluations. The manuscript management system is completely online and includes a very quick and fair peer-review system, which is all easy to use. 